\title{
An unusual consequence of urinary catheter neglect: A giant bladder stone
}

\author{
Archana Agarwal, Justin Gould
}

\begin{abstract}
Introduction: Indwelling urinary catheters cause a variety of complications including infections, pain and bleeding. Sometimes, the catheter becomes encrusted and blocked. Case Report: $A$ 66-year-old male was presented with increasing suprapubic pain for about two months because of a poorly draining Foley catheter. Two years earlier, the patient had undergone a transurethral resection of the prostate (TURP) gland. He was given a Foley catheter and asked to follow-up in a week. He did not follow-up or change the catheter for two years. The catheter could not be removed. A computed tomography scan of the abdomen showed a large encrustation of $5.0 \times 5.2 \times 5.5 \mathrm{~cm}$ surrounding the Foley. The patient underwent open suprapubic cystostomy with intact retrieval of stone along with the catheter. Conclusion: Indwelling Foley catheters frequently become encrusted and may become difficulty to remove. The developments of giant encrustations are unusual. Such giant encrustations usually need surgery for removal.
\end{abstract}

Keywords: Indwelling urinary catheters, Bladder stone formation, Encrustations, Proteus Mirabilis

Archana Agarwal ${ }^{1}$, Justin Gould ${ }^{2}$

Affiliations: ${ }^{1} \mathrm{MD}$, Medical Director Hospitalist Services,

Department of Medicine, Steward Carney Hospital,

Dorchester, Massachusetts, USA; ${ }^{2} \mathrm{MD}$, Attending

Physician, Department of Urology, Steward Carney Hospital,

Dorchester, Massachusetts, USA.

Corresponding Author: Archana Agarwal, Medical Director Hospitalist Services, Department of Medicine, 2100 Dorchester Avenue, Dorchester, Massachusetts, USA02124; Ph: +16172964000, Ext No: 2732; Fax: +16174743855;

Email:archana.agarwal@steward.org

Received: 15 January 2014

Accepted: 18 February 2014

Published: 01 June 2014

\section{How to cite this article}

Agarwal A, Gould J. An unusual consequence of urinary catheter neglect: A giant bladder stone. Int $\mathrm{J}$ Case Rep Images 2014;5(6):427-430.

doi:10.5348/ijcri-201481-CR-10392

\section{INTRODUCTION}

Indwelling urinary catheters cause a variety of complications including infections, pain and bleeding [1]. Sometimes, the catheter becomes encrusted and blocked [1]. We present a case of a giant bladder stone formation in a patient who did not change the catheter for more than two years.

\section{CASE REPORT}

A 66-year-old male with a past medical history of benign prostatic hypertrophy (BPH) was admitted for increasing suprapubic pain for about two months because of a poorly draining Foley catheter. His past medical history was significant for hypertension but the patient was non-compliant with medications. The patient denied any allergies and was not taking any medications at that time. He denied smoking or drinking alcohol. He did not have a family history of urinary stone formation or any history of bladder or prostate cancer. Two years earlier, the patient had transurethral resection of the prostate (TURP). He was given a Foley catheter and asked to follow-up in a week. The patient did not follow-up for two years, nor did he get the catheter changed during this time. He said he was taking care of his dying brother who lived in another state.

On physical examination, blood pressure of the patient was $166 / 79 \mathrm{mmHg}$ and his pulse was $70 / \mathrm{min}$. He was afebrile and breathing at 16 breaths per minute. His chest was found to be clear to auscultation. His heart sounds 
were normal. His abdomen was soft, non-tender and non-distended, and the bladder could not be palpated. His genital exam revealed a circumcised phallus with a non-draining Foley that had efflux of urine around it. His rectal exam revealed a very hard and enlarged prostate. The laboratory examination revealed a normal white blood cell count of $7200 / \mathrm{mm}^{3}$ (normal value $4500-1100 /$ $\mathrm{mm}^{3}$ ). His creatinine level was $1.84 \mathrm{mg} / \mathrm{dL}$ (normal value 0.6-1.4 mg/dL). The Foley catheter could not be removed after the catheter balloon was deflated with a syringe, and the balloon port was cut. A computed tomography (CT) scan of the pelvis was done which showed a large encrustation of $5.0 \times 5.2 \times 5.5 \mathrm{~cm}$ surrounding the Foley (Figure 1).

The patient was treated for high blood pressure with amlodipine. He was given fluids and levofloxacin, as the urine showed pyuria at the time of admission. The patient underwent open suprapubic cystostomy (Figure 2). The stone was retrieved intact, along with the catheter (Figure 3). His urine grew mixed flora. Levofloxacin was continued for two weeks. The patient did not develop any complications from the procedure. He was discharged with the catheter. His catheter was removed at followup, two weeks later and he passed a voiding trial. His creatinine improved to $1.4 \mathrm{mg} / \mathrm{dL}$ (normal value $0.6-1.4$ $\mathrm{mg} / \mathrm{dL})$.

\section{DISCUSSION}

Almost half of the patients with long-term catheters will experience blockage [1]. Bacteria in the urine form a biofilm on the surface of the catheter protecting it from antibiotics and host defenses [2]. When a patient becomes infected with urease producing organisms, the $\mathrm{pH}$ of the urine rises, and the once soluble calcium and magnesium phosphates deposit on surface of the catheter, forming encrustations [3]. Most of the stones are either composed of struvite (magnesium-ammonium-sulfate) or apatite (calcium-phosphate) [4]. The bacteria most commonly associated with the production of stones is Proteus mirabilis, although a wide variety of other organisms have been implicated [5]. Encrustations can occur either in the lumen of the catheter or outside of it [6].

Once the encrustation has formed, patients can develop symptoms of obstruction such as abdominal pain and leakage around the catheter. If not timely removed, the patient can develop pyelonephritis, sepsis or even die [7]. There are various methods described in literature as to how encrustations can be removed with minimal invasive techniques. These include extracorporeal shock wave lithotripsy (ESWL) [8], intraluminal pneumatic lithotripsy [9], and directly crushing the encrustations with a rigid cystoscope inserted through a suprapubic cystostomy tract [6]. However, in our patient, the encrustation was so large that any non-invasive technique would have been technically difficult. Thus, we had to perform an open suprapubic cystostomy.

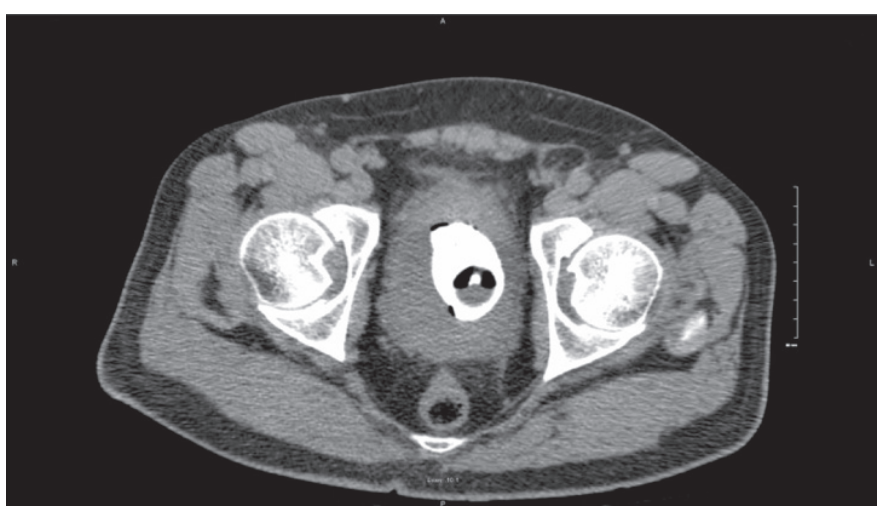

Figure 1: Computed tomography scan of the pelvis without contrast showed a large encrustation $5 \times 5.2 \times 5.5 \mathrm{~cm}$ surrounding the Foley balloon.

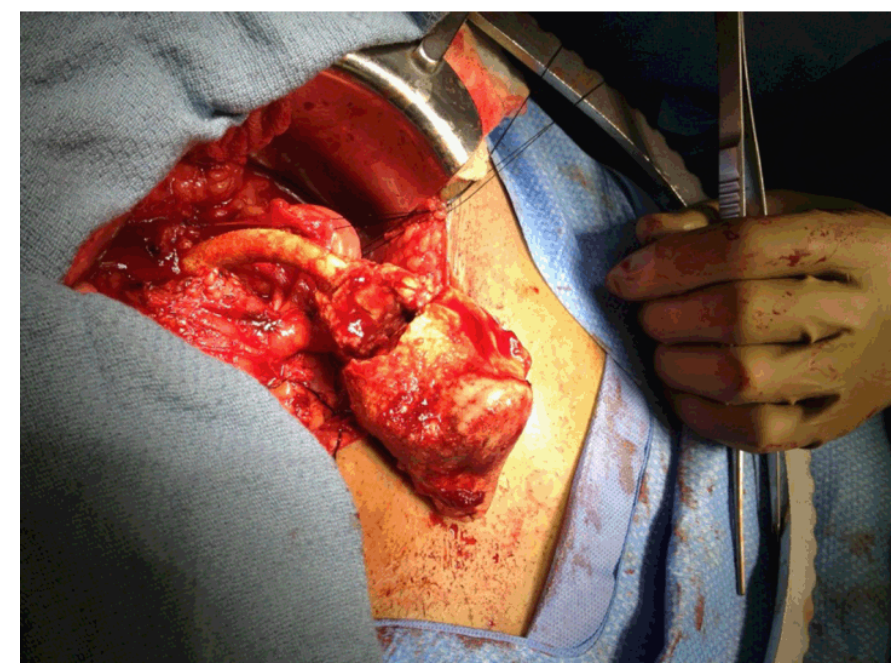

Figure 2: Open suprapubic cystolithotomy with intact retrieval of the stone and the Foley catheter.

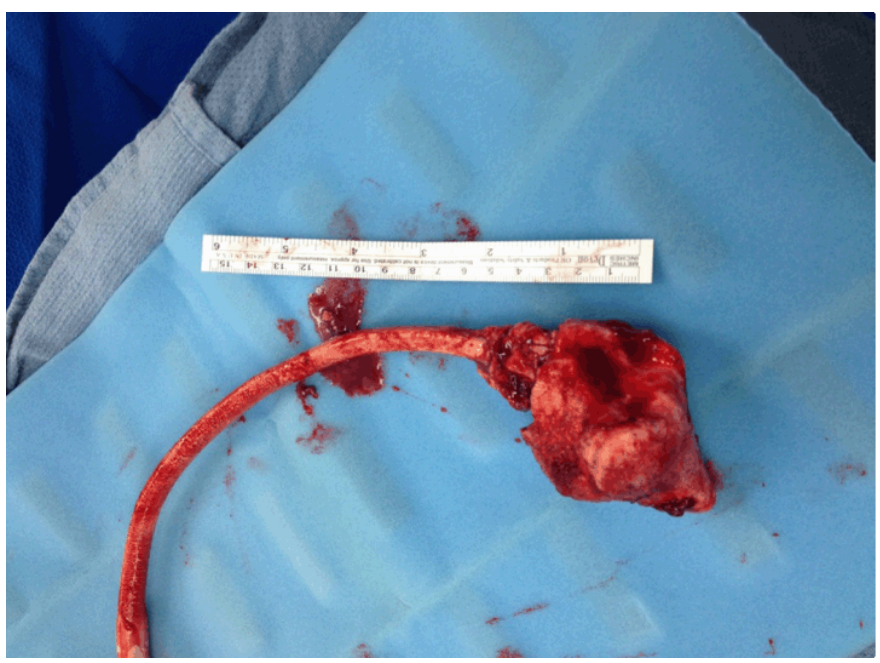

Figure 3: Intact Foley with stone.

There are no proven techniques to prevent bladder stone formation, and one catheter may not be better than the other [4]. However, one study on health volunteers showed that increasing fluid and citrate intake could prevent the encrustations [9]. A critical pH is needed 
for crystalline deposit to occur. This is also known as the nucleation $\mathrm{pH}$ [10]. Increasing the fluid and citrate intake could decrease this $\mathrm{pH}[10]$. Another option is to promptly treat Proteus mirabilis as soon as it appears in the patient's urine. However, it needs to be stressed that antibiotic therapy is not an option in chronic blockers [4].

\section{CONCLUSION}

We presented a case of giant bladder stone formation in a patient who did not change an indwelling urinary catheter. Indwelling Foley catheters frequently become encrusted and may become difficulty to remove. The developments of giant encrustations are unusual. Such giant encrustations usually need surgery for removal.

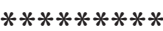

\section{Author Contributions}

Archana Agarwal - Substantial contributions to conception and design, Acquisition of data, Analysis and interpretation of data, Drafting the article, Revising it critically for important intellectual content, Final approval of the version to be published

Justin Gould - Acquisition of data, Analysis and interpretation of data, Revising it critically for important intellectual content, Final approval of the version to be published

\section{Guarantor}

The corresponding author is the guarantor of submission.

\section{Conflict of Interest}

Authors declare no conflict of interest.

\section{Copyright}

(C) 2014 Archana Agarwal et al. This article is distributed under the terms of Creative Commons Attribution License which permits unrestricted use, distribution and reproduction in any medium provided the original author(s) and original publisher are properly credited. Please see the copyright policy on the journal website for more information.

\section{REFERENCES}

1. Kohler-Ockmore J, Feneley RC. Long-term catheterization of the bladder: Prevalence and morbidity. Br J Urol 1996;77(3):347-51.

2. Trautner BW, Darouiche RO. Role of biofilm in catheter-associated urinary tract infection. American Journal of Infection Control 2004;32(3):177-83.

3. Broomfield RJ, Morgan SD, Khan A, Stickler DJ. Crystalline bacterial biofilm formation on urinary catheters by urease-producing urinary tract pathogens: A simple method of control. J Med Microbiol 2009;58(Pt 10):1367-5.

4. Stickler DJ, Feneley RC. The encrustation and blockage of long-term indwelling bladder catheters: A way forward in prevention and control. Spinal Cord 2010;48(11):784-90.

5. Stickler D, Ganderton L, King J, Nettleton J, Winters C. Proteus mirabilis biofilms and the encrustation of urethral catheters. Urol Res 1993;21(6):407-11.

6. Ho CC, Khandasamy Y, Singam P, Hong Goh E, Zainuddin ZM. Encrusted and incarcerated urinary bladder catheter: What are the options? Libyan J Med 2010;5.

7. Stickler DJ, Zimakoff J. Complications of urinary tract infections associated with devices used for long-term bladder management. J Hosp Infect 1994;28(3):17794.

8. Kunzman SA, Srinadh ES, Lala SM, Albusaidi Q. Management of retained encrusted urethral catheter with extracorporeal shockwave lithotripsy. Indian Journal of Urology 2002;19(1):83-4.

9. Canby-Hagino ED, Caballero RD, Harmon WJ. Intraluminal pneumatic lithotripsy for the removal of encrusted urinary catheters. The Journal of Urology 1999;162(6):2058-60.

10. Suller MT, Anthony VJ, Mathur S, Feneley RC, Greenman J, Stickler DJ. Factors modulating the pH at which calcium and magnesium phosphates precipitate from human urine. Urol Res 2005;33(4):254-60. 
Access full text article on other devices

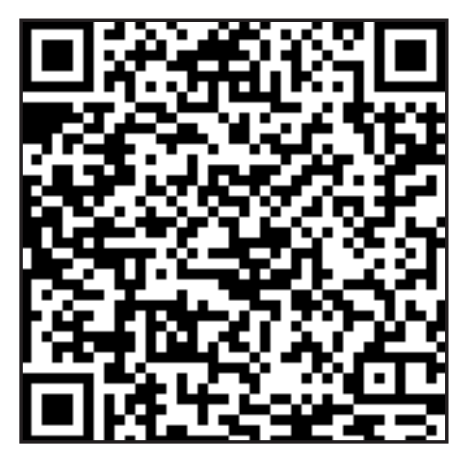

Access PDF of article on other devices

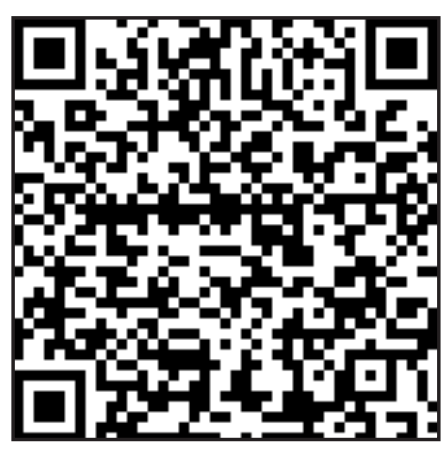

